\title{
: \\ Barriers in access to mental health care - results from the World Mental Health Survey Initiative Portugal
}

Manuela Silva 1,2, Ana Antunes 1,2, Sofia Azeredo-Lopes², Joana Zózimo1,2, Graça Cardoso 1,2, José Miguel Caldas de Almeida1,2 1 Lisbon Institute of Global Mental Health. Comprehensive Health Research Centre (CHRC), Nova Medical School, Nova University of Lisbon 2 Nova Medical School, Nova University of Lisbon manuela.silva@gmail.com

\section{Background}

Understanding the reasons for not accessing mental health care is an important step in reducing the treatment gap ${ }^{1,2}$. The aim of this study was to evaluate the sociodemographic and clinical factors associated with the use of mental health treatment, and with barriers to treatment.

\section{Materials and Methods}

- Data from the 2009 National Mental Health Survey were used.

- 12-month mood, anxiety and substance use disorders were assessed with the CIDI 3.0.

- Participants were asked about 12-month treatment and reasons for non-treatment.

- Logistic regression models were used to assess the association between sociodemographic (education, employment, and marital status) and clinical variables (type of mental disorder and disability) with the use of care, and with barriers to treatment (low perceived need, structural and attitudinal barriers).

- All models were adjusted for age, gender, and the presence of psychical disorders.

Table 1. Logistic regression model of the association between the use of care or barriers to treatment and sociodemographic and clinical factors

\begin{tabular}{|c|c|c|c|c|}
\hline & \multirow{2}{*}{$\begin{array}{c}\text { Use of services } \\
\text { Any health treatment }\end{array}$} & \multicolumn{3}{|c|}{ Barriers to use of services } \\
\hline & & Low-perceived need & Attitudinal Barriers & Structural barriers \\
\hline & $\mathrm{OR}(95 \% \mathrm{Cl})$ & OR $(95 \% \mathrm{Cl})$ & OR $(95 \% \mathrm{Cl})$ & OR $(95 \% \mathrm{Cl})$ \\
\hline \multicolumn{5}{|l|}{$\begin{array}{l}\text { Sociodemographic } \\
\text { characteristics }\end{array}$} \\
\hline \multicolumn{5}{|l|}{ Marital status ${ }^{\mathbf{a}}$} \\
\hline Divorced/Widowed & $1.50(0.76-2.97)$ & $0.72(0.33-1.57)$ & - & - \\
\hline Single & $0.38(0.20-0.70)^{\star}$ & $1.77(1.01-3.08)^{\star}$ & - & - \\
\hline \multicolumn{5}{|l|}{ Educational levelb } \\
\hline None/primary & $0.52(0.25-1.11)$ & - & $2.90(1.42-5.90)^{\star}$ & - \\
\hline Basic/secondary & $0.42(0.24-0.73)^{\star}$ & - & $1.70(1.01-2.85)^{\star}$ & - \\
\hline \multicolumn{5}{|l|}{ Employment statusc } \\
\hline Unemployed & - & - & - & $3.76(1.29-10.92)^{\star}$ \\
\hline Retired or other & - & - & - & $0.86(0.11-6.98)$ \\
\hline \multicolumn{5}{|l|}{ Clinical characteristics } \\
\hline Mood disorders ${ }^{d}$ & $4.19(2.72-6.46)^{\star \star}$ & $0.16(0.09-0.30)^{\star \star}$ & & \\
\hline Anxiety disorders ${ }^{d}$ & & $0.50(0.28-0.90)^{\star}$ & & \\
\hline Substance disorders ${ }^{d}$ & & & $0.27(0.10-0.70)^{\star}$ & \\
\hline Disability & $2.43(1.33-4.46)^{\star}$ & & & \\
\hline
\end{tabular}

a) Reference category: married; b) Reference category: university level; c) Reference category: working or student; d) Reference category: absence ${ }^{*} p<0.05 ;{ }^{* *} p<0.01 ;{ }^{* \star *} p<0.001$

\section{Conclusions}

- Mental disorders remain untreated for many individuals in Portugal.

- Strategies to increase health literacy are needed for those with a lower education level, and for single people.

- Affordable and accessible health care is crucial for those unemployed.

\section{References}

1. Alonso J, Liu Z, Evans-Lacko S, et al (2018) Treatment gap for anxiety disorders is global: Results of the World Mental Health Surveys in 21 countries. Depress Anxiety 35(3):195-208. 